\title{
Issues in Translation: translating from English to Maithili
}

\section{P.K. Choudhary}

\begin{abstract}
Translation from Foreign languages to Indian languages requires a lot of skills, tools and techniques. There are a lots of translation theories available in the market but I have not come across any such theory which can address all the issues, difficulties and techniques required for a good translation in a particular language. There are issues like Word-order, Grammatical categories, Syntax and Technical words etc. where we need to apply our own knowledge about the language in question while translating from one language to other. To make translation more acceptable for common people, sometimes, it is required to transliterate or put English words in brackets so that it can be understood by reader properly as it has been used in source language. Translation also require glossary of technical words, if it is not available in the target language, it will be more difficult for translator to translate and get desired result. There are other equipments required for translation i.e. modern bilingual dictionary, thesaurus, and some available material in the language which will help while translating from Source to Target language. If there are no such tools available in the language as in the case of Maithili, it will be more difficult task for translator. This paper will discuss above mentioned issues and their possible solution to be adhered, while translating from English to Maithili for better result.
\end{abstract}

Key words: Translation, Culture, Lexical, Syntax

\section{Introduction}

Translation has played critical role in inter-human communication, providing access to important texts for

\section{Translation Today}


scholarship, business and religious purposes. As world trade has grown due to globalization, so as the importance of translation.

As we know, compared to other disciplines, "Translation Studies" is much younger. It is only in 1972, James Holms suggested a discipline called "Translation Studies" came in to being and now it is unquestionably one of the main discipline used throughout the academic circles. It has been enriched with scholars from various fields. Translation Studies is multilingual and interdisciplinary in its nature. It is encompassing through Languages, Linguistics, Philosophy, Communication studies and Cultural studies. It has witnessed rise and fall of theoretical approaches from word to word translation, from sense to sense translation, from linguistic equivalence theory to cultural equivalence theory and from functional theories of translation to philosophical equivalence theory of translation. Each of these theories has its own effect and relevance on the discipline and has enriched the Translation theory.

There are two types of translation in the world, i.e., paraphrase and imitation (word for word). These have been defined by Lefevere (1977: 73)

Paraphrase strives to conquer the irrationality oflanguages, but only in a mechanical way. (...) The paraphrasist treats the elements of the two languages as if they were mathematical signs which may be reduced to the same value by means of addition and subtraction. (...) Imitation on the other hand, submits to the irrationality of languages; it grants that one cannot render a copy... $\quad$ - Lefevere (1977: 73)

In the above statement mathematical signs look forward to the concept of structural linguistics, terminology and machine translation. He is probably the first scholar to make a distinction between 'genuine translation' and 'mere interpreting' where the latter one refers to both oral and written translation of everyday business text. 
These two methods are recognized in the English speaking community as "foreignization" and "domestication". Schleiermacher emphasizes on the "bending" of the target language to create a deliberately contrived foreignness in the translation. He himself used this method while translating Plato. During the course of time the maxims presented by this great theologian has been taken up by many scholars throughout the world from Victorian England to Germany of the 1920s.

Different scholars have different views regarding theories. Here is another extract from Weaver (1955) who thinks that there are a few differences between paraphrase and imitation.

While mere word for word translation would be inadequate, only a few items on the left or right of the word concerned need to be considered to ensure a correct translation (Weaver, 1955)

Translation from foreign languages to Indian languages requires a lot of skills, tools and techniques. There are lots of translation theories available but I have not come across any such theory which can address all the issues, difficulties and technique required for a good translation in a particular language. There are issues like word-order, grammatical categories, syntax and technical words etc. where we need to apply our own knowledge about the language in question while translating from one language to the other. To make translation more acceptable for common people, sometimes, it is required to transliterate or put English words in brackets so that it can be understood by the reader properly as it has been used for in source language. Translation also requires glossary of technical words, if it is not available in the target language, it will be more difficult for translator to translate and get desired result. There are other equipments required for translation, i.e., modern bilingual dictionary, thesaurus, and some available material in the language which will help while translating from the source to the target language. If there are no such tools available in the language as in the case of Maithili, it will 
be more difficult task for translator. This paper will discuss above mentioned issues and their possible solution to be adhered while translating from English to Maithili for better result.

\section{Problems in translating technical terms}

One of the first steps in analysis is careful study of key words in order to find a good lexical equivalent in the target language. There are certain requirements which needs to be taken care of, i.e., dialect, education level, age, bilingualism and social level of users as these things can have an effect on the form of target language.

It is always difficult to translate technical terms into Indian languages even though we may have words for it. It creates problems in making consistency throughout the text, i.e., air, we may use 'həwa' but in phrase like "Air tight situation", it is confusing if we use translation for word "air". To avoid inconsistency and confusion we were compelled to transliterate it. Sometimes technical words formed by us are so difficult for general speakers of the language to understand and pronounce that it will be better to transliterate source words, i.e., dhumrəśəktə viśraməaləyə for "railway station".

There are some other important issues to be taken care of while translating. We have been losing our words day by day due to influence of foreign languages and due to globalization. As to be part of global world, we need to have an international language to interact with world people. There is also a general tendency that knowing a foreign language means you will get jobs in the market easily. In such scenario, people prefer to speak English or even if speaking in their mother-tongue prefer to mix English words acquired from different means. This trend is killing our own words and giving place for foreign words. While translating from English to Indian languages, if we use Indian words or in other words, terms from our own language will be odd in comparison to English words, e.g., word for grave, kitchen and even match-box 
etc. For more details in this regard please see (Choudhary, 2013)

Words with same form and function, lexical equivalents when concepts are unknown because of differences in geography, custom, beliefs made by using generic words and a descriptive modification, e. g.,'fierce animal', need to be taken care of during translation.

Same lexical items can be used in different cultures differently. As in U S (I had a dream) and in U K (I saw a dream). These two sentences are used in different places (culture) for same meaning.

Taboo in one culture may be useful word in another culture. There are various such examples across the cultures. Thus cultural differences may create differences in usage of word, e.g., 'niru' in Kannada is used for drinking water whereas the same word in Maithili means sacred water got after performing worship to the idol.

Situational context of a word is another important area to be taken care of as words reflect emotions and attitudes. Lack of context causes ambiguity. For example: 'Air tight situation', when translated into Maithili, we need to take care of lexical equivalence in our language. There are some examples showing such cases below which I came across while translating smart phones guidelines:

1. Picture quality optimized for advertisement display is set. विज्ञापन प्रदर्शनक लेल फोटोक गुणवत्ता ऑप्टीमाइज्ड/अनुकूल सेट कायल गेल।

2. It releases background color adjustment. ई बैकग्राउंड रंगक एडजस्टमेन्ट/सुधार निर्गत करेत अछि।

3. The speed of the fan in each set is automatically adjusted. प्रत्येक सेट/ बक्सा में पंखा केर गति अपने आप/स्वतः एडजस्ट भए/सुधारि 136 Translation Today 
जाइत अछि/

\section{Camera Setting- कैमराक सेटिंग ।}

\section{Start/Stop Slideshow- स्लाइडशो शुरु / बन्द करु।}

There are certain words which always create confusion when translated into Maithili, e.g., update, saving, processing, default, network, account, overwrite etc. To avoid ambiguity and maintain consistency in a given text, we have to either put English words in bracket by the side of translated words or there is no need to translate these words rather we may transliterate them. For clarification we may consider the following statement by Nida and Taber (1969).

Translating consists in reproducing in the receptor language the closest natural equivalent of the source-language message, first in terms of meaning and secondly in terms of style. (Nida and Taber 1969:12)

There is another important issue to be taken care of during translation. There are different uses of pronoun across languages, i.e., animate and inanimate; inclusive in comparison with exclusive; honorific in comparison with non-honorific and gender sensitive language in comparison with gender non-sensitive language. Below we will discuss such pronouns in Maithili and difficulty in translating such pronouns.

There is another phrase called idiom. It needs to be taken special care while translating. As idioms are semantically one unit; one should not break and substitute one word for another to avoid offensive or socially unacceptable expression.

Real translation is transparent, it does not hide the original, it does not steal its light, but allows the pure language, as if reinforced through its own medium, to fall on the original work with greater fullness. This lies above all in the power of literalness 
in the translation of syntax, and even these points to the word, not the sentence, as the translator's original element. (Lefevere 1977: 102)

Thus message in a text is more important than lexicon, syntax and other elements of language. Our primary goal should be to capture the meaning of the original text and then present it in target language's natural order. Such translation will convey meaning to the reader without creating ambiguity.

\section{Word order differences and its effects on translation}

As we know, Maithilii has nominative-accusative constructions. English has Subject-Verb-Object order whereas Maithili has Subject-Object-Verb order. If there is different word order in the languages in question then other differences too follow, some of these are mentioned below: The Indirect Object (IO) precedes the Direct Object (DO) in unmarked word order. The verb final languages have postpositions. The genitives precede the governing noun. The marker of comparison precedes the standard of comparison. Time adverbial $(T)$ precede place adverbials $(P)$. The complementizer follows the embedded sentence as a post-sentential marker. The adjectives precede the head noun. Question words occur in-situ in Maithili. The subject pronoun can be dropped. Similarly, if the verb is carrying the agreement markers of the $\mathrm{IO}$ and DO, they can be dropped. It has been accepted by scholars that contrastive analysis of languages is very useful in translation.

6. həm ja-itə chi

I go-INF be

'I go'

7. mohən ghər ja-rəhəl chə-thI

Mohan home go-PROG be-3SG,H 
'Mohan is going home.'

8. radha mohən-kẽ ek-ta am de-l-əin

Radha Mohan-ACC one-CL mango give-PST-3SG,H

'Radha gave a mango to Mohan.'

9. sunita әpən pəti-kẽ citthi lıkhə-l-əin

Sunita self husband-ACC letter write-PST-3SG,H

'Sunita wrote a letter to her husband.'

10. rəmesh suresh-kẽ ek-ta pothi de-l-əin

Ramesh Suresh-ACC one-CL book give-PST-3SG,H

'Ramesh gave a book to Suresh.'

Therefore, it is necessary for a translator to know natural word-order in their languages. As expectancy chain shows, certain words or phrases are expected to follow certain others. It differs from language to language. Or may be parameter determines word order in a language. Wrong word-order, awkward phrasing, and collocation classes can create awkward translation. It is expected from translators to have very good command over both target and source languages. It means one should know the basics of the language before going to translate a text.

\section{Grammatical categories and its translation in target language}

There may be change in categories while translating from English to Indian languages, i.e., adjective becomes Noun, Verb becomes Adverb or vice versa. Agreement, Tense, Aspect \& Mood (TAM) and other factors of grammar needs to be confronting properly. Languages differ in their instrument for mentioning time, 
tense and mood that need to be taken care of. Here I mean one should not follow the norms of source language while translating.

11. stroke- $\mathrm{n}$ - a soft gentle movement of your hand across something: हाथ फेरब सहलाएब -- Give the cat a stroke. बिलाइर के सहला दिऔक। $(n \rightarrow v$.)

12. oil- v -to put oil on something to make it work more smoothly: तेल देब, भरब -- You should oil your bike more often. तोरा अक्सर अपन फटफटिया मे तेल देबाक चाही ।(Vor N?)

13. cousin, may be translated into Maithili in three ways, ममियौत, पिसियौत, पितियौत ।

14. beautiful- (adjectives in predicate position in English become adverb when translated into most of Indian languages). It is very beautiful. ई बड सुन्दर अछि।

15. sad /sæd/ adj. (sadder, saddest)-unhappy: उदास, श्रीहीन - । liked my school and I was sad to leave. हमरा अपन विद्यालय पसिन्न छल आ हम ओकरा छोड़ि उदास भोलों। (adjective becoming adverb when translated into Maithili)

Wrong grammatical forms or obscure constructions, semantic reunite for users, user's level and education are some of the essential things to be known before translating a text. Though, as explained above message is more important but artlessness of language must be maintained throughout.

\subsection{Agreement marking in Maithili and its effects on translation}

As mentioned above, Maithili has three-way distinction of pronouns in second person, namely, əhã 'you honorable' tũ 'you non-honorable' əpne'you extra honorable'. Honorific marker plays very important role in agreement marking in Maithili. There is

\section{Translation Today}


always confusion when we translate such sentences into Maithili as explained above. Even for nouns for example:

16. mohən ghər ja-i(tə) chə-thI

Mohan home go-INF be-3SG,H

'Mohan goes home.'

17. mohən ghər ja-itə əch-I

Mohan home go-INF be-3SG,NH

'Mohan goes home.'

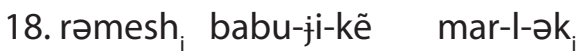

Ramesh father-H-ACC beat-PST-3SG,NH

'Ramesh beat father.'

19. babu-ji $i_{i}$ rəmesh-kẽ mar-l-əin

Father-H Ramesh-ACC beat-PST-3S,GH

'Father beat Ramesh'.

20. kənija puja kərə-it-heti

Bride worship do-INF-3SG,F,H

'Bride may be worshiping.'

21. chəũra-səb səb-ta am gachhə-mesə todI-le-l-ək boy-PL all-CL mango tree-PP pick-take-PST-3SG, $\mathrm{NH}$ 'boys have picked all the Mangoes from the tree.'

It has been shown above that honorific marker plays important role in agreement marking. It is not possible to catch such honorificity in English pronouns. Therefore, back translation cannot be done. Even translating from English to Maithili may 
require extra effort to understand and put such pronouns in Maithili. Moreover, only native speakers of Maithili can understand such differences between honorific and non-honorific pronouns or nouns. As shown in above examples Noun Phrase determines agreement on the verb.

\subsection{Tense and Aspect system in Maithili and its effect on translation}

Maithili verb system has Verb+Tense+Agreement order. As shown above honorificity of noun or pronoun dominates the Agreement. Adverb precedes the main verb as shown in (22). Most of the times Maithili has Main Verb+ Auxiliary Verb+ Tense+ Agreement order. But there are constructions like (24) where Main Verb + Tense + verb + Agreement order exists.

22. choũra tej dəudə-it əch-I

boy fast run- INF be+3SG,NH

'Boy runs fast.'

23. ek-ta sundər kənija məndır-me path kər-əit-chə-l-ih One-CL beautiful lady temple-PP read do-INF-be-PST-3SG,F,H 'One beautiful lady was reading secret book in the temple.'

24. həm hunka ghər-pər ge-l-rəh-i

I his home-PP go-PST-stay-3SG,NH

'I went to his home.'

25. mohən-kẽ əpən kaj kər-ba-me kono sənkoc nəhı ho-bak Mohan-ACC self work do-FUT-PP any shame not happen-FUT cahi-yən 
should-3SG,H

'Mohan should not feel any shame in doing his own work.'

As shown in above examples there are different 'be' forms in Maithili which varies as per nouns and their class. Generally, we try to capture the source language meaning and in such scenario we may disrupt naturality of the target language. We need to avoid such disruption and maintain target language rules in terms of word formation, pronunciation, and grammatical categories in natural order.

\section{Cultural differences between English and Maithili}

Language and culture cannot be separated as a language creates word/lexicon according to their needs for their culture and rituals. Thus one language is rich in one area and other in others. Customs and Rituals differ amongst language community and to explain certain customs in a particular language may be difficult as $\mathrm{M} \mathrm{N}$ Srininvasa's book titled "Social Change in Modern India" has some such examples. In this book, he discussed about the Lingayat caste and their rituals that cannot be found elsewhere.

This is one of the important areas where we come across difficulties while translating bilingual dictionaries. Most of bilingual dictionaries of India are from English to Indian languages or vice versa. While preparing bilingual dictionaries we come across cultural differences which are difficult to bridge or create words for expressions like the following:

26. boy.friend/'borfrend/ n. a boy or man that you have a romantic relationship with: प्रेमी, प्रियतम -- Can my boyfriend come to the party? (की) हमर प्रेमी भोजमे आबि सकैत छथि ?

27. girl· friend / 'g3:Ifrend/ n. 1. a girl or woman that you are having a romantic relationship with: प्रेयसी, प्रियतम -- I'm going out with my girlfriend tonight. आइ राति हम अपन प्रेयसीक सँग बाहर 
जा रहल छी। 2. a girl or woman who is the friend of another girl or woman: सखी (we do not have concept of such things in Indian context as it is used in western languages)

28. bread /bred/ n. ( no pl.) a food made by mixing flour and water and then baking it: डबलरोटी, पाँवरोटी -- a loaf of bread. पैघ डबलरोटी। a slice of bread. पाँवरोटी केर टुकडी । (we do have bread made of flour of wheat but different than that of bread used in English)

29. date /deIt/ n. 2. an arrangement to meet someone you like in a romantic way: समय, भेंट - आबंध (अपन प्रिय स्त्री पुरुष सं पूर्व निर्धारित समय आ स्थान पड़ भेंटब) I have got a date tonight. हमरा आई रातिक समय भेटल अछि। (we do not have such sense of date in our culture as conveyed by the English word above)

30. hel·lo/hə'ləu/ also hallo, hullo the usual word that we say when we meet someone or begin to talk on the telephone: हेलो, हेल्लो (फोन पर वा भेंट भेला पर अभिवादनक शब्द) - हेलो। (I think we do not have a word matching semantics of hello in our culture, instead we have other means/lexicon for such purpose)

31. fi•anc•ée / fi:'onsei/n. a woman who has promised to marry a particular man: होबय बला पत्नी - His fiancee is called Susan. हुनकर होबय वाली पत्नी के नाम सुजन छनि ।

In such cases it is better to explain things in note or keep the transliteration of the English words that convey message to reader better. As translation of such words which has no cultural values or such practice is not available in the target language culture may create confusion or illusion in the minds of the reader.

\section{Conclusion}

Translation is not merely transcoding of words or sentences from 
one language into another, but a complex phenomena in which source text information will be transferred under a new functional, cultural and linguistic condition, preserving all aspects of source language as far as possible.

Translation should be accurate, clear and natural. As shown above to get such translation we should follow certain norms. Following extract will clear certain illusion:

We translate neither words nor languages but texts. Text translation indicates a demarcation; because every text is embedded in a situation which itself is not language. This situation is the cultural, historical, economic or social space in which a text speaks to us. (Klaus Berger and Hans-Michael, 1986: 159)

There are needs of detailed syntactic rules, an extensive lexicon and high-speed processing of ambiguities would be an adequate basis for a perfect type of translation known as fully automatic high quality translation. While translating our primary goal is to present the source language text into the target language in simple and natural way. As mentioned earlier, meaning of the source text is more important than theory, syntax and other elements of language to be presented in target language.

Here is another extract about the type of translation:

Despite all contrary assertions translation is based on understanding and not primarily on theoretical reasoning. It does not move only in linguistic behavior patterns or react in set linguistic reflexes; it is open for what has not been delimited. (Klaus Berger and Hans-Michael, 1986: 158)

\section{Abbreviations}

3- Third Person

$\mathrm{NH}$ - Non-honorific

ACC-Accusative Case

PROG-Progressive

CL- Classifier

PST-Past Tense 
FUT-Future Tense

H-Honorific

INF-Infinite
PP-Post Position

PL-Plural

Acknowledgements: Thanks Professor Awadhesh Kumar Mishra and Prof. Saratchandran Nair for their valuable comments and corrections which make this paper clearer than it was.

\section{REFERENCES}

Choudhary, P. K. 2012. Issues in making bi-lingual dictionary, paper presented at SPSTU Hyderabad, 5-6, December, 2012.

Choudhary, P.K. 2013. Causes and Effects of Super-stratum Language Influence, with Reference to Maithili, The journal of Indo-European Studies, Volume 41, Number 3 \& 4, Fall/Winter 2013.

Gentzler, Edwin, 2001. Contemporary Translation Theories. Cromwell press Ltd. London.

Holmes, James S. 1987. "The name and nature of translation studies." Indian Journal of Applied Linguistics 13 (2): 9-24.

Berger, Klaus; Paepcke, Fritz; Speier, Hans-Michael.1986. Im Übersetzen leben. Übersetzen und Textvergleich, Christa von Baum, Berlin.

Lefevere, A. 1977. Translating Literature. The German Tradition from Luther to Rosenzweig (Approaches to Translation 4). Assen/ Amsterdam: Van Gorcum.

Nida, Eugene A. and Charles Taber. 1969. The Theory and Practice of Translation. Leiden: Brill.

Schleiermacher, F. 1813/2004. 'On the different methords of translating', in Lawrence Venuti (ed.) 2004. The Translation Studies Reader, 2nd Edition, London and New York: Routledge, pp.43-63.

Weaver, Warren. 1955. Translation, a memorandum, 15.07.1949." In Machine Translation of Languages, W.N. Locke and A.D. Booth (eds.), 15-23.New York.

\section{Translation Today}

